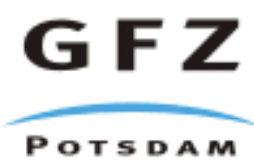

Originally published as:

Bohnhoff, M., Makris, J. (2004): Crustal structure of the southeastern Iceland-Faeroe Ridge (IFR) from wide aperture seismic data. - Journal of Geodynamics, 37, 2, 233-252,

DOI: 10.1016/j.jog.2004.02.004. 


\title{
Crustal structure of the southeastern Iceland-Faeroe Ridge (IFR) from wide aperture seismic data
}

\author{
Marco Bohnhoff*, Jannis Makris \\ Institute of Geophysics, University of Hamburg, Bundesstraße 55, 20146 Hamburg, Germany \\ Received 30 May 2003; received in revised form 3 February 2004; accepted 9 February 2004
}

\begin{abstract}
The aseismic Iceland-Faeroe-Ridge (IFR) is of central importance in reconstructing the opening of the North Atlantic Ocean. To investigate the crustal structure of the IFR at its southeastern part we conducted a wide aperture seismic survey across the IFR from the Iceland Basin to the Norway Basin. Seismic energy was generated by two 60-litre sleeve guns and recorded by 42 ocean-bottom seismometers (OBS). Kinematic and dynamic forward modeling by two-point ray tracing was applied to develop a $2 \mathrm{D}$ velocity-depth model. The accuracy of the model obtained is better than $5 \%$ for both velocity and depth of interfaces. We find a Moho depth of $23 \mathrm{~km}$ below the crest of the ridge that decreases to about $15 \mathrm{~km}$ at either end of the line. The upper part of the crust exhibits P-wave velocities between 5.7 and $6.3 \mathrm{~km} / \mathrm{s}$ that increase towards the Norway Basin. The lower crust is more homogeneous with $v_{p}$ ranging from 6.6 to $7.0 \mathrm{~km} / \mathrm{s}$. Upper and lower parts of the crust are separated by a first order discontinuity. Amplitudes $\left(\mathrm{P}_{\mathrm{m}} \mathrm{P}\right)$ and arrival times $\left(\mathrm{P}_{\mathrm{n}}\right)$ of wide-angle phases indicate upper-mantle velocities of $7.9 \mathrm{~km} / \mathrm{s}$. Furthermore we analyzed PS-converted phases for upper crustal depth levels and find $\mathrm{a} \mathrm{v}_{\mathrm{p}} / \mathrm{v}_{\mathrm{s}}$ ratio of $1.73 \pm 0.04$ equal to a Poisson's ratio of 0.25 with no significant lateral variations along the seismic line. On the crest of the ridge we identified a basalt layer embedded within the sedimentary sequence that was also penetrated by deep sea drilling and dated to $43 \pm 3.3$ million years. Below the basalt layer we observed a low-velocity layer that is identified as Mesozoic sediment that was also observed to either end of the basalt. We conclude that the southeastern part of the IFR is composed of stretched continental crust and thus part of Paleo-Europe rather than oceanic crust formed by the Iceland hot spot. This conclusion is supported by the distribution of magnetic anomalies that allow identifying the passive continental margin approximately $100 \mathrm{~km}$ to the NW of our seismic line.
\end{abstract}

(C) 2004 Elsevier Ltd. All rights reserved.

* Corresponding author at current address: GeoForschungsZentrum, Potsdam, Telegrafenberg, 14473 Potsdam, Germany. Fax: + 49-331-288-1328.

E-mail address: bohnhoff@gfz-potsdam.de (M. Bohnhoff). 


\section{Introduction and tectonic setting}

The eastern part of the North Atlantic is extensively studied by geophysical methods due to both scientific and economic motives. Coastal and shelf regions have been the targets of numerous high-resolution multi channel seismic (MCS) surveys aiming to access the hydrocarbon potential. Deeper offshore-regions beyond $1000 \mathrm{~m}$ waterdepth have been investigated by potential-field methods (gravity and magnetic surveys) to resolve the crustal structure and reconstruct it in time and space. In addition, wide aperture seismic profiles provided essential information in understanding the physical properties of the crust and the upper mantle and played a central role in studying the area. This technique allows to resolve crustal structure with high accuracy and to penetrate the lower crustal and uppermost mantle depth levels. By densely spacing recording units and shots the determination of lateral velocity changes of the structure down to the crustmantle boundary is possible (e.g. Makris and Ginzberg, 1987; Trey et al., 1999; Bohnhoff et al., 2001). Moreover, this technique allows the imaging of structures below energy-absorbing layers such as basalt (e.g. Samson, et al., 1995) and thrust belts. This is of particular interest when investigating flood basalt provinces such as the North Atlantic Volcanic Province (NAVP) or passive volcanic margins.

The aseismic Iceland-Faeroe Ridge, named IFR hereafter, is located in the eastern North Atlantic Ocean between Iceland and the Faeroe Islands (see Fig. 1a). It is one of the major gateways responsible for northern hemisphere climate development. The IFR is a shallow structural high with smooth bathymetry reaching a minimum of $400 \mathrm{~m}$ (see Fig. 1b). To the NW, the ridge is limited by Iceland, the surface expression of the volcanically active Iceland hot spot. Iceland is composed of basaltic material with values for $\mathrm{v}_{\mathrm{p}}$ and $\mathrm{v}_{\mathrm{s}}$ typical for oceanic crust. The crustal thickness, however, is 4-5 times thicker than normal oceanic crust (Palmason, 1971; Gebrande et al., 1980; RRISP, 1980; Zverev et al., 1976; Staples et al., 1997; Foulger et al., 2003). To the SE the IFR abuts against the Faeroe Islands that have been identified as being of continental origin with a crustal thickness of about $30 \mathrm{~km}$ (e.g. Bott et al., 1974) and covered by a $3-5 \mathrm{~km}$ thick basaltic layer that is about 50-60 million years old (Tarling and Gale, 1968). Previous geophysical investigations of the IFR focusing on its crustal structure have revealed contradicting results. Zverev et al. (1976) presented a model of thick continental crust below the IFR and Strauch (1970) and McKenna (1972) discussed it as a Tertiary land bridge in the North Atlantic. In contrast, a number of authors (e.g. Bott et al., 1971; Fleischer, 1971; Bott and Gunnarsson, 1985; Richardson et al.; 1998, Smallwood et al., 1999) proposed a crust of oceanic origin of this structure with a thickness between 20 and $35 \mathrm{~km}$ formed between 55 and 40 million years b.p. by volcanic activity in association to a hot spot. The question of whether the IFR was part of PaleoEurope prior to break-up of the North-Atlantic at 58 million years (White, 1989) or whether it developed by magma flow of the Iceland hot spot and thus can be regarded as a plume trace is of importance for the analysis of Paleo-water circulation on both local and global scales (see e.g. Myhre and Thiede, 1995).

Here, we present the results of a wide aperture seismic survey that was conducted to obtain a detailed resolution of the crustal structure of the IFR at its southeastern part. The aim was to resolve the crustal structure from the uppermost sedimentary sequences down to the base of the crust from the Iceland Basin in the SW across the crest of the ridge to the Norway Basin in the NE using a large number of stand alone ocean-bottom seismographs (OBS). Preliminary model- 

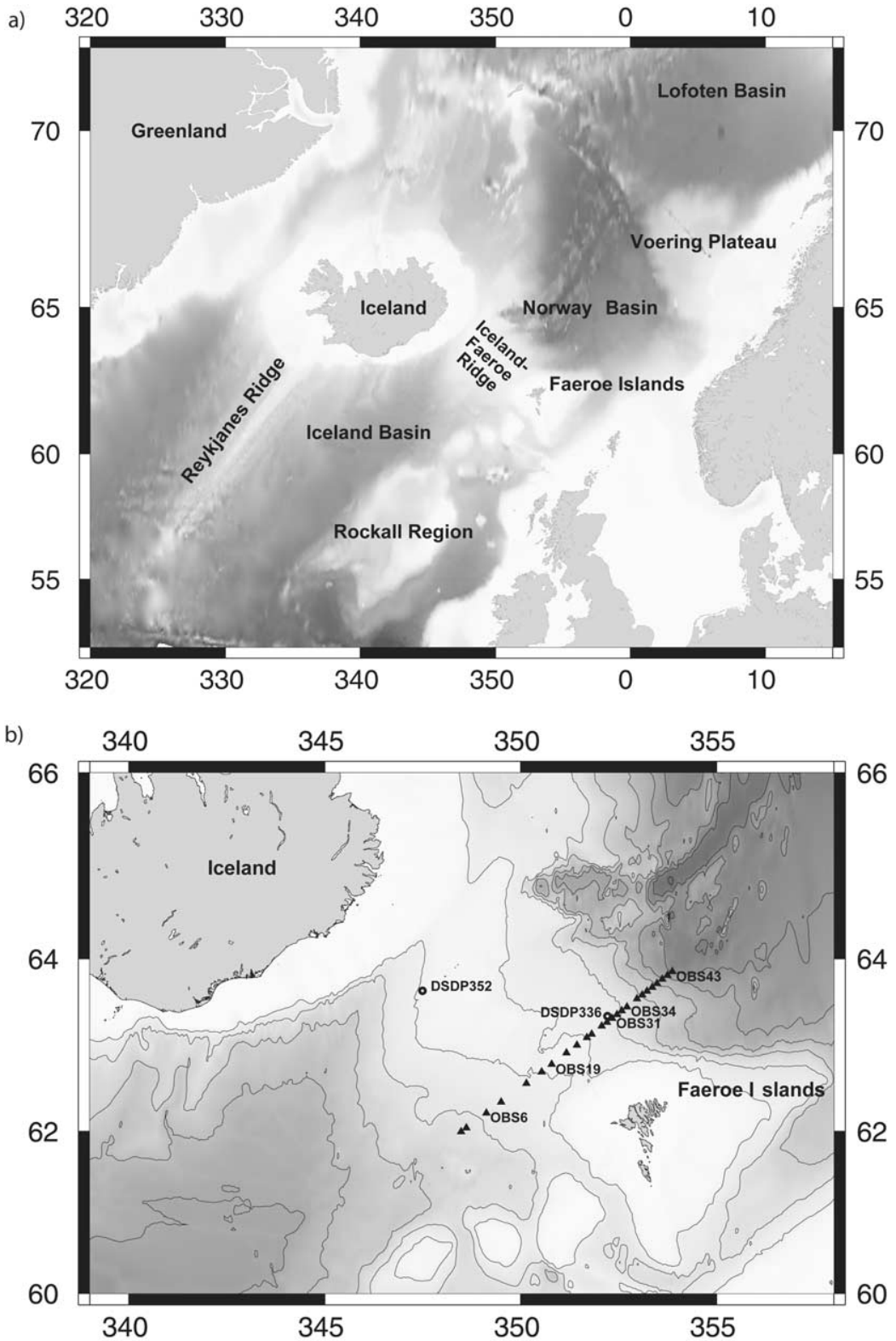

Fig. 1. (a) Bathymetric map and main tectonic units of the North Atlantic between Greenland and NW Europe containing the Iceland-Faeroe Ridge (IF interpret the crust beneath the ridge to be formed by sea-floor spreading between 55 and $40 \mathrm{R}$ ). (b) Enlarged map of the Iceland-Faeroe region and location of the seismic line presented in this study. Triangles mark OBS positions that were selected for modeling, annotated stations are key-positions and discussed later in the text. Circles mark the drilling locations on the IFR as part of the Deep Sea Drilling Program. Contour lines and subsequent shading mark $500 \mathrm{~m}$ intervals of waterdepth. 
ing results for this line were presented by Makris et al. (1995). In this study we have thoroughly re-evaluated the entire data set starting from the base with a refined digitizing procedure of the analogue recorded data. Furthermore, we have optimized the standard processing procedure commonly used for seismic data to our special purpose. This re-evaluation results in a well-constrained model, which is presented below.

\section{The experiment}

The field campaign was conducted under the direction of the Institute of Geophysics, Hamburg University in co-operation with the Shirshov Institute of Oceanology of the Russian Academy of Sciences (Moscow and Gelendzik) in 1993. A total of 44 ocean-bottom seismographs (OBS) were spaced equidistantly at $8.2 \mathrm{~km}$ along the seismic line resulting in a total length of $370 \mathrm{~km}$. The profile strikes $\mathrm{N} 55^{\circ} \mathrm{E}$ and crosses the IFR perpendicularly to its strike with the aim to get a detailed resolution of its crustal structure and post-rifting evolution. The waterdepth reaches a minimum of $413 \mathrm{~m}$ at the crest of the ridge and increases towards either end of the line to $1075 \mathrm{~m}$ (SW) and $3165 \mathrm{~m}(\mathrm{NE})$, respectively. In Fig. 1b a bathymetric map and selected OBS positions are plotted.

Two 60-liter sleeve-guns served as the energy source and were operated at 150 bar and fired in two-minute intervals generating a signal with a dominating frequency of $8 \mathrm{~Hz}$. The vessel speed was kept constant at 4-5 knots resulting in a distance of approximately $250 \mathrm{~m}$ between shots. The total number of shots fired along the line was 1435. Each OBS was equipped with a three-component seismometer of $4.5 \mathrm{~Hz}$ eigenfrequency. Deployment and recovery positions were surveyed and fixed using the Global Positioning System (GPS) with an average accuracy of $50 \mathrm{~m}$. Final underwater positions of the individual OBS were estimated using the water-wave arrivals of the shots near each station and an average velocity of $1480 \mathrm{~m} / \mathrm{s}$ for the sound propagation in seawater. The technical equipment of this OBS type allowed a $300 \mathrm{~h}$ continuous recording (Makris and Möller, 1989).

\section{Data evaluation}

The wide aperture seismic method applied here is termed WARRP (Wide Aperture Reflection and Refraction Profiling; Makris et al., 1999). This method requires the deployment of a large number of stand-alone seismic stations distributed along a line or 3D geometry. The same type of data logger is used for both offshore and onshore observations. The aim of a WARRP survey is to generate a sufficiently expanded seismic line to observe wide-angle reflections from shallow structures as well as from deeper reflectors. Once the recording units are deployed, all stations remain stationary during shooting and record all shots along the complete line length. Using a WARRP receiver geometry, subsurface structures are mapped by wide-angle reflections even if the velocity contrast between layers is small. The evaluation of traveltime WARRP data in common receiver gather sections and subsequent kinematic and dynamic forward modeling using the two-point raytracing method (Červeny and Psenćik, 1981, 1983; Zelt and Smith, 1992; Zelt, 1997) permits the development of well constrained and reliable velocity-depth models. 
The data obtained along the seismic line presented here was recorded in analogue form and later digitized at a common $125 \mathrm{~Hz}$ sampling rate. Once the data was digitized, a number of processing steps were applied to the data in order to generate common receiver gather sections for both the vertical and horizontal components of each recording unit. An automatic gain control (AGC) with varying windows between 0.5 and $4.0 \mathrm{~s}$ was applied to improve the identification of weak reflections or first arrivals, respectively. The entire data set was filtered using a Kaiser Band pass filter of $3-15$ or $3-10 \mathrm{~Hz}$ and, finally, a linear move out reduction was applied to all sections using $6.0 \mathrm{~km} / \mathrm{s}$ as reduction velocity. This specific velocity was chosen to get the optimal resolution of diving waves in the igneous basement.

Upon completion of processing, the travel time sections were analyzed. In general, the quality is good to excellent with sufficient signal to noise ratio (SNR) to detect first arrivals even at wide angle offsets $(>50 \mathrm{~km}$ ) while a number of sections allow the identification of arrivals to offsets of $100 \mathrm{~km}$ and more. Interestingly, a remarkable difference in data quality was observed along the line. Whereas almost every OBS from the northeastern part of the line showed good or excellent data quality, only ten stations from the southwestern part were selected for modeling. The others did not contain a sufficient SNR. Still the quality of these ten stations was not as good as along the northeastern part of the line. All stations were equipped with the same hardware (recording units, sensors, ground-coupling mechanism). Thus, we believe that the difference in data quality between both parts of the line is caused by water currents that produce a significantly higher noise level in the southwestern part of the line on the slope from the ridge down to the Iceland Basin. Finally, we selected 25 stations out of the 42 OBS that obtained seismic energy. In these sections, both reflected and refracted phases where picked and used as input for the two-point ray tracing in order to develop a 2D velocity-depth model by kinematic and dynamic forward modeling using the SEIS83 software package by Červeny and Psenćik (1981, 1983). Once a 1D velocity-depth distribution was determined for each station based on apparent velocities and intercept times these were linearly combined and used as the initial 2D model. The model was then developed starting at the near surface interfaces and progressively modeling the deeper parts of the section. The lower boundary of the section was fixed to $30 \mathrm{~km}$ depth as no reflector was identified below. The absolute accuracy of the model is depth-dependent: We find that the accuracy does not exceed $2 \%$ for the shallower parts $(<10 \mathrm{~km}$ depth) and $5 \%$ for the deeper parts for both $\mathrm{v}_{\mathrm{p}}$ values and depth of interfaces. The depth error for a modeled interface at $15 \mathrm{~km}$ depth is therefore less than $0.75 \mathrm{~km}$ whereas $\mathrm{v}_{\mathrm{p}}$ within the upper crust may vary by up to $0.12 \mathrm{~km} / \mathrm{s}$.

\section{Results}

\subsection{Crustal structure}

The Moho depth reaches a maximum of $23 \mathrm{~km}$ below the crest of the IFR in the central part of the profile (see Fig. 2). The crust is subdivided into an upper $\left(\mathrm{v}_{\mathrm{p}}=5.7-6.3 \mathrm{~km} / \mathrm{s}\right)$ and a lower part $\left(\mathrm{v}_{\mathrm{p}}=6.6-7.0 \mathrm{~km} / \mathrm{s}\right)$ by a first order discontinuity with a velocity increase of $0.3-0.5 \mathrm{~km} / \mathrm{s}$. The Moho depth decreases remarkably to about $15 \mathrm{~km}$ towards either end of the line. Towards the Norway Basin a lateral change in both crustal thickness (decreasing) and velocity (increasing) 


\section{Iceland Basin}

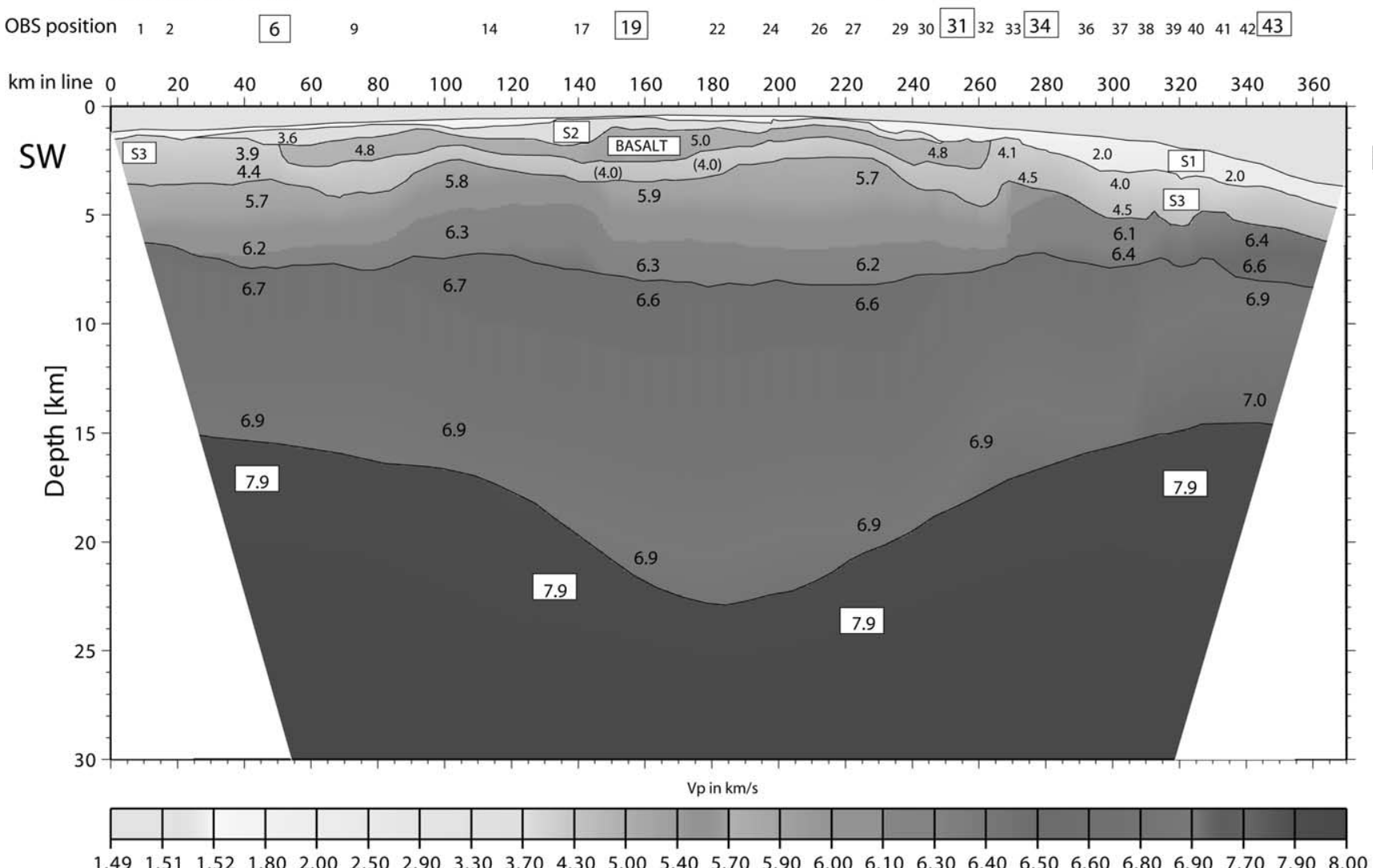

Fig. 2. 2D P-wave velocity depth model for the seismic line across the southeastern part of the Iceland-Faeroe-Ridge (see Fig. 1 for location). A total of eight layers were resolved separated by interfaces with velocity contrasts between $0.15 \mathrm{~km} / \mathrm{s}$ (water to lowermost sediment) and $1.7 \mathrm{~km} / \mathrm{s}$ (lowermost sediment to basement). Framed OBS positions mark key-positions that are discussed in the text. The uppermost layer is the water column. S1-S3 marks sedimentary layers. The basalt layer is marked in the Figure. The layers below S3 represent upper continental crust, lower continental crust and upper mantle (see discussion in the text). Numbers within the model indicate P-wave velocities while those in brackets were determined indirectly (see text for details). The vertical exaggeration is 6.6. 


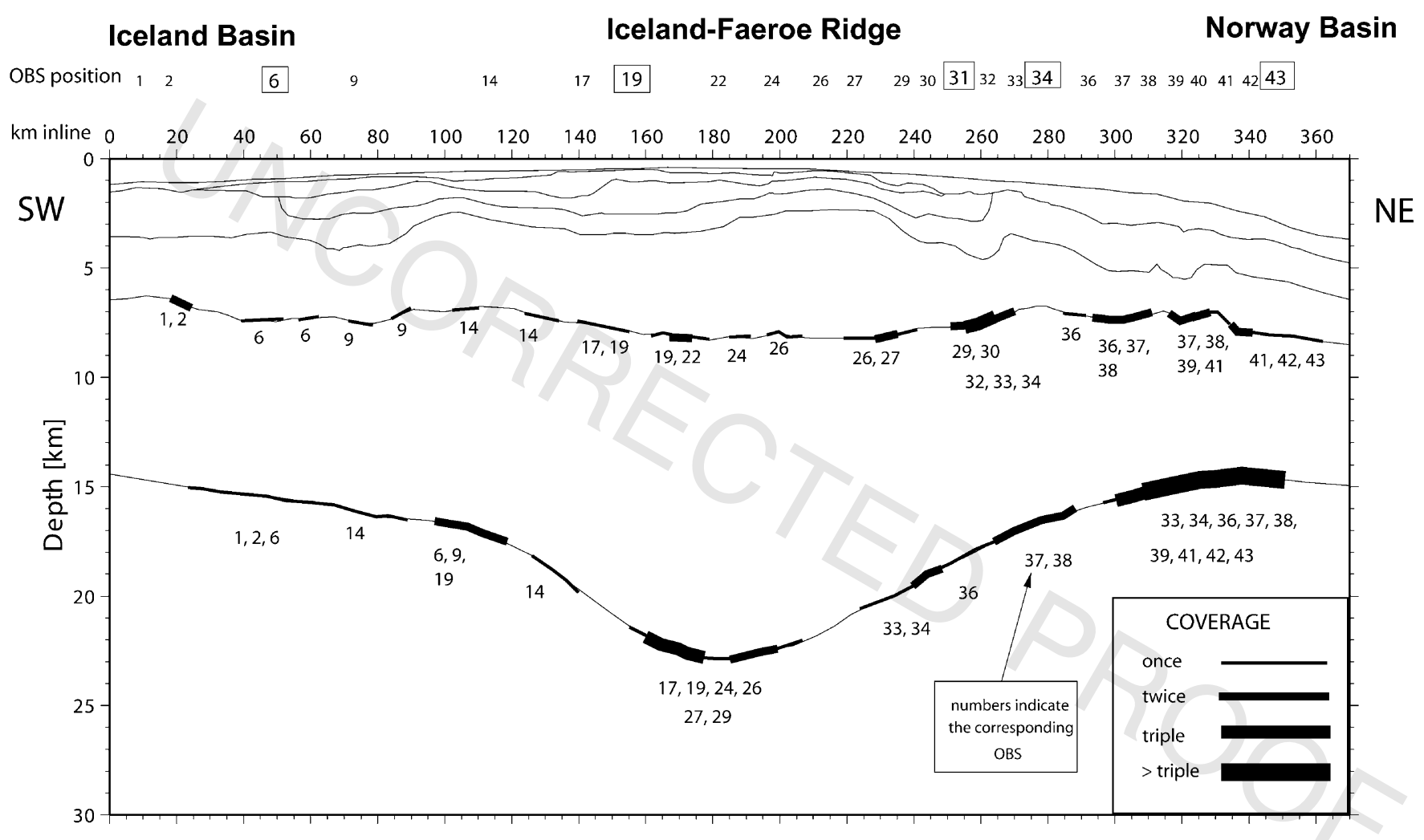

Fig. 3. Coverage scheme for first order discontinuities identified along the seismic line. A clear difference between both parts of the profile is explained by the difference in data quality (see text for details). Thickness of interfaces increases with coverage as shown in the legend. Framed OBS positions mark key-positions that are discussed in the text. The vertical exaggeration is 6.6. 


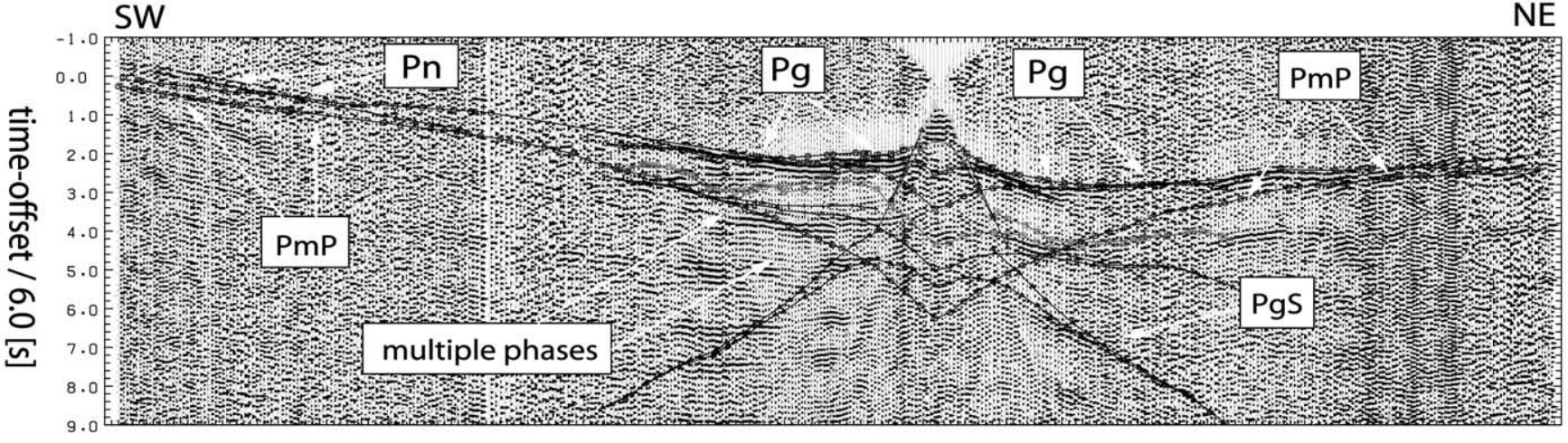

NE

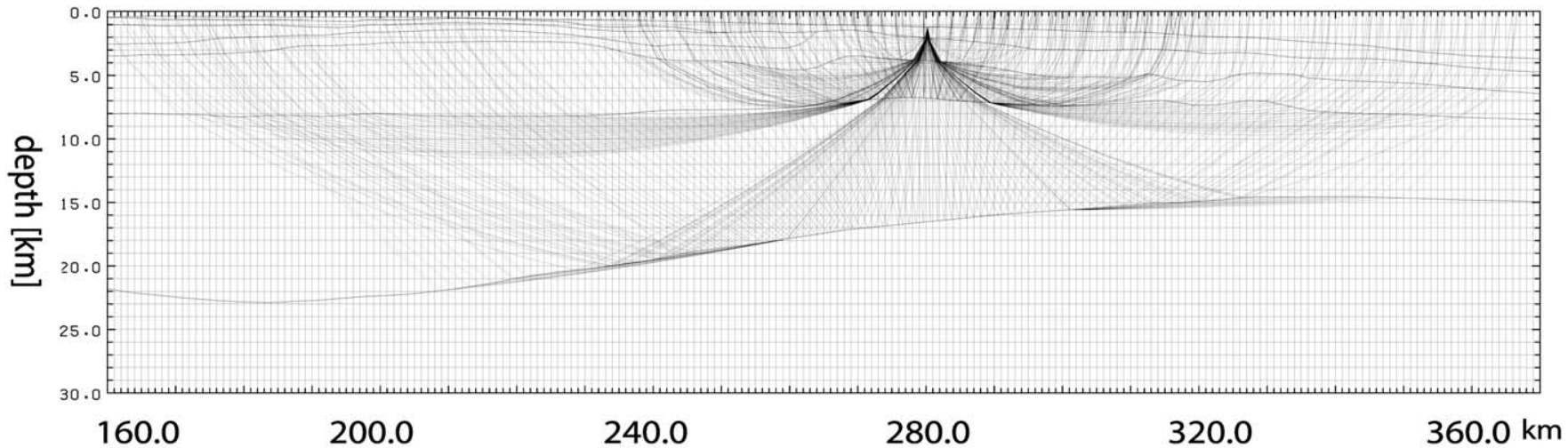

Fig. 4. Results obtained from OBS34 (located at northeastern part of the seismic line, see Fig. 1b). The upper part combines the recorded seismic data and computed traveltime curves; the lower part shows the ray-paths trough the model. A Kaiser Band pass filter between 3 and $10 \mathrm{~Hz}$ was applied to the seismic data, the section is plotted with an AGC window of $2.0 \mathrm{~s}$ and amplitudes are standardized to maximum within each trace. The reduction velocity is $6.0 \mathrm{~km} / \mathrm{s}$. Seismic phases are named here in accordance with the international standards: $\mathrm{P}_{\mathrm{g}}$ is the diving wave within the upper crust, $\mathrm{P}_{\mathrm{i}} \mathrm{P}$ is the reflection at the intracrustal boundary, $\mathrm{P}_{\mathrm{m}} \mathrm{P}$ is the reflection at the lower boundary of the crust (Moho) and $\mathrm{P}_{\mathrm{n}}$ is the diving wave in the uppermost mantle. Furthermore we termed $\mathrm{P}_{\mathrm{g}} \mathrm{S}$ the PS-converted phase at the igneous basement and $\mathrm{P}_{\mathrm{b}}$ the diving wave within the basalt layer. Other phases are not explained here, as they do not play a major role in the presented figures. 
was observed. Such a strong lateral variation was not identified on the southwestern part of the seismic line towards the Iceland Basin. This might be caused by the comparatively poor data quality and subsequent ray-coverage along this part of the line (see Fig. 3). However, the southwestern end of the line does not reach waterdepth levels as deep as in the NE. Consequently, the seismic line might not cover the oceanic crust below the Iceland Basin. In Fig. 3, the reliability of the sediment-basement transition and deeper reflection/refraction horizons are shown for the entire line length. Obviously a large difference can be recognized between either half of the line. We explain the comparatively poor coverage for the southwestern part of the line by the difference in data quality between stations in the NE and SW, respectively, as discussed above. OBS34 (see Fig. 4) serves as a good example for the data quality along the northeastern part of the seismic line. There, first arrivals can be identified to an offset of $120 \mathrm{~km}$. Note the abrupt decrease in SNR at about $40 \mathrm{~km}$ offset to the SW. This marks the northeastern termination of the basalt layer and is discussed later in the text. Wide aperture reflections from the Moho $\left(\mathrm{P}_{\mathrm{m}} \mathrm{P}\right)$ are identified on either side whereas to the $\mathrm{SW}$ we have also identified $\mathrm{P}_{\mathrm{n}}$ phases. Both $\mathrm{P}_{\mathrm{m}} \mathrm{P}$ amplitudes and $P_{n}$ arrival times point to $v_{p}=7.9 \mathrm{~km} / \mathrm{s}$ in the uppermost mantle. No layer with $7.0 \leqslant v_{p} \leqslant 7.8$ $\mathrm{km}$ that would indicate an underplated body was identified in any section. In the near field of OBS 34 (see Fig. 5) two distinct sedimentary layers with $\mathrm{v}_{\mathrm{p}} \approx 2.0(\mathrm{~S} 1)$ and $4.0 \mathrm{~km} / \mathrm{s}(\mathrm{S} 3)$ are observed. A remarkable difference of their apparent velocity to either side is explained by increasing water depth and sedimentary thickness to the NE. Moving along the line further to the NE towards the transition from the IFR to the Norway Basin we refer to OBS43 (see Fig. 6). As this station is the last to the NE, the end of the seismic line fixes the maximum offset to record seismic energy from the NE to $20 \mathrm{~km}$ whereas to the SW energy was observed to $95 \mathrm{~km}$ distance. Again the near field allows identifying two sedimentary layers being slightly thinner than at OBS34. At this part of the seismic line, coherent travel-time curves along the entire length were observed due to a rather homogeneous lateral layering (different to the central part of the line that includes the basalt layer). Again, as at OBS34, we obtained wide-angle phases pointing to uppermost mantle velocities of $7.9 \mathrm{~km} / \mathrm{s}$. The enlarged part shows wide angle offsets (Fig. 6b) show the part of the section where the $\mathrm{P}_{\mathrm{m}} \mathrm{P}$ phase approaches the $\mathrm{P}_{\mathrm{g}}$ phase. At about $50 \mathrm{~km}$ offset the $\mathrm{P}_{\mathrm{n}}$ phase becomes first arrival.

In a number of seismic sections (see OBS34, 43, 6, 19 and 31 in Figs. 4 and 6-9) we identified converted phases, predominantly $\mathrm{P}_{\mathrm{g}} \mathrm{S}$. These allowed the determination of the $\mathrm{v}_{\mathrm{p}} / \mathrm{v}_{\mathrm{s}}$ ratio in the upper crust and therefore the Poisson's ratio. Evaluation of converted phases indicated a $v_{p} / v_{s}$

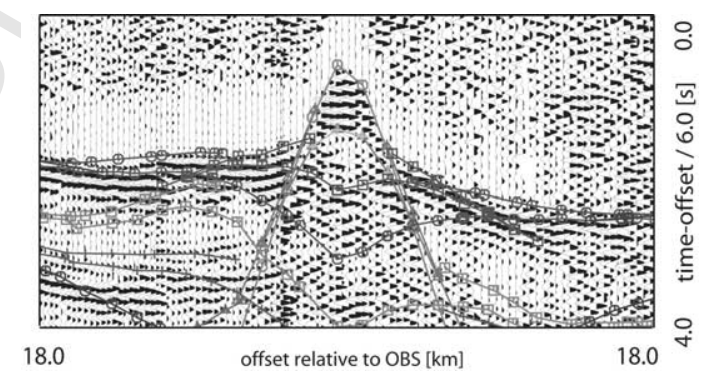

Fig. 5. Near-field section of OBS 34 including the computed travel-time curves. Details are discussed in the text. 
ratio of $1.73( \pm 0.04)$ equal to a Poisson's ratio of 0.25 . Thus, the upper crust has ideal elastic behavior which is of major importance in drawing conclusions on the crustal origin of this part of the IFR. We refer to this point later in the text. Unfortunately, the SNR on the horizontal sections is not as good as on the vertical ones and no information concerning $\mathrm{v}_{\mathrm{p}} / \mathrm{v}_{\mathrm{s}}$ could be observed for deeper structures as no converted phases were identified in the sections at the appropriate offsets.
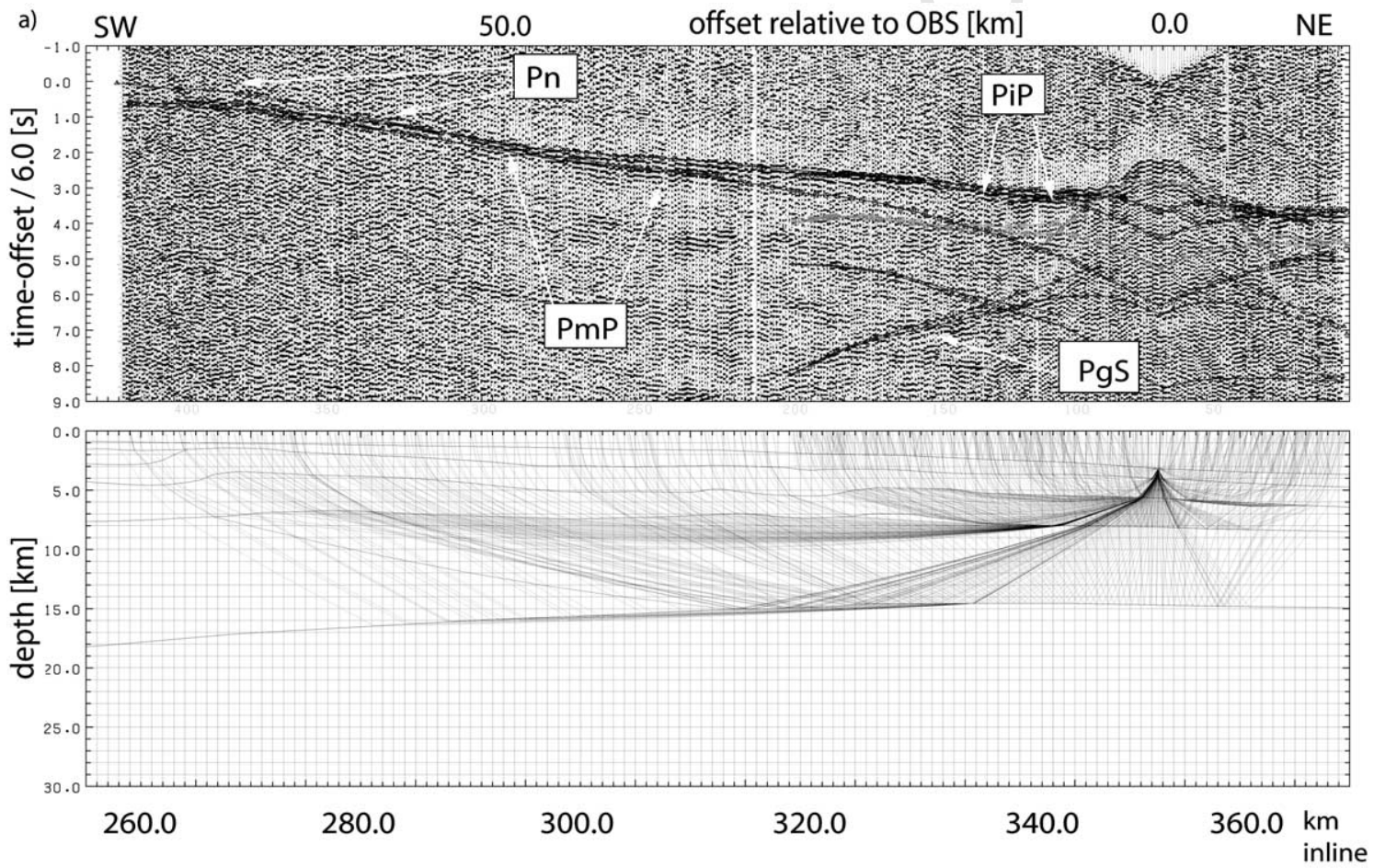

b)

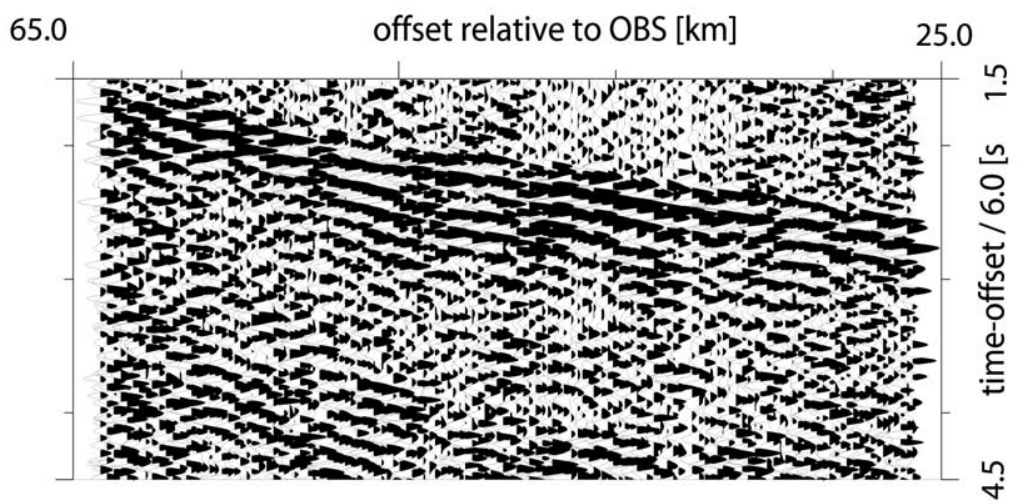

Fig. 6. (a) Data obtained from OBS 43 (located at the northeastern end of the seismic line, see Fig. 1b). The excellent signal-to-noise ratio allows correlation of the crust-mantle boundary. For explanation of phases see Fig. 4 . (b) Enlarged part of OBS 43 highlighting the arrivals of the wide-angle phases $\left(\mathrm{P}_{\mathrm{g}}, \mathrm{P}_{\mathrm{m}} \mathrm{P}\right.$ and $\left.\mathrm{P}_{\mathrm{n}}\right)$. 


\subsection{Sedimentary structure}

The sedimentary cover above the igneous basement varies between 2.0 and $4.2 \mathrm{~km}$ in thickness and is subdivided into four layers with $\mathrm{v}_{\mathrm{p}}$ ranging from 1.65 to $5.0 \mathrm{~km} / \mathrm{s}$ (see Fig. 2 and sections in Figs. 5, 8 and $9 \mathrm{~b}$ ). The thickness of the uppermost sedimentary layer (S1) with $\mathrm{v}_{\mathrm{p}}$ of about 1.65 $\mathrm{km} / \mathrm{s}$ varies between 0 (not resolved) and $1500 \mathrm{~m}$; this layer was identified along most parts of the line. Towards the Norway Basin this layer reaches its maximum thickness in combination with a
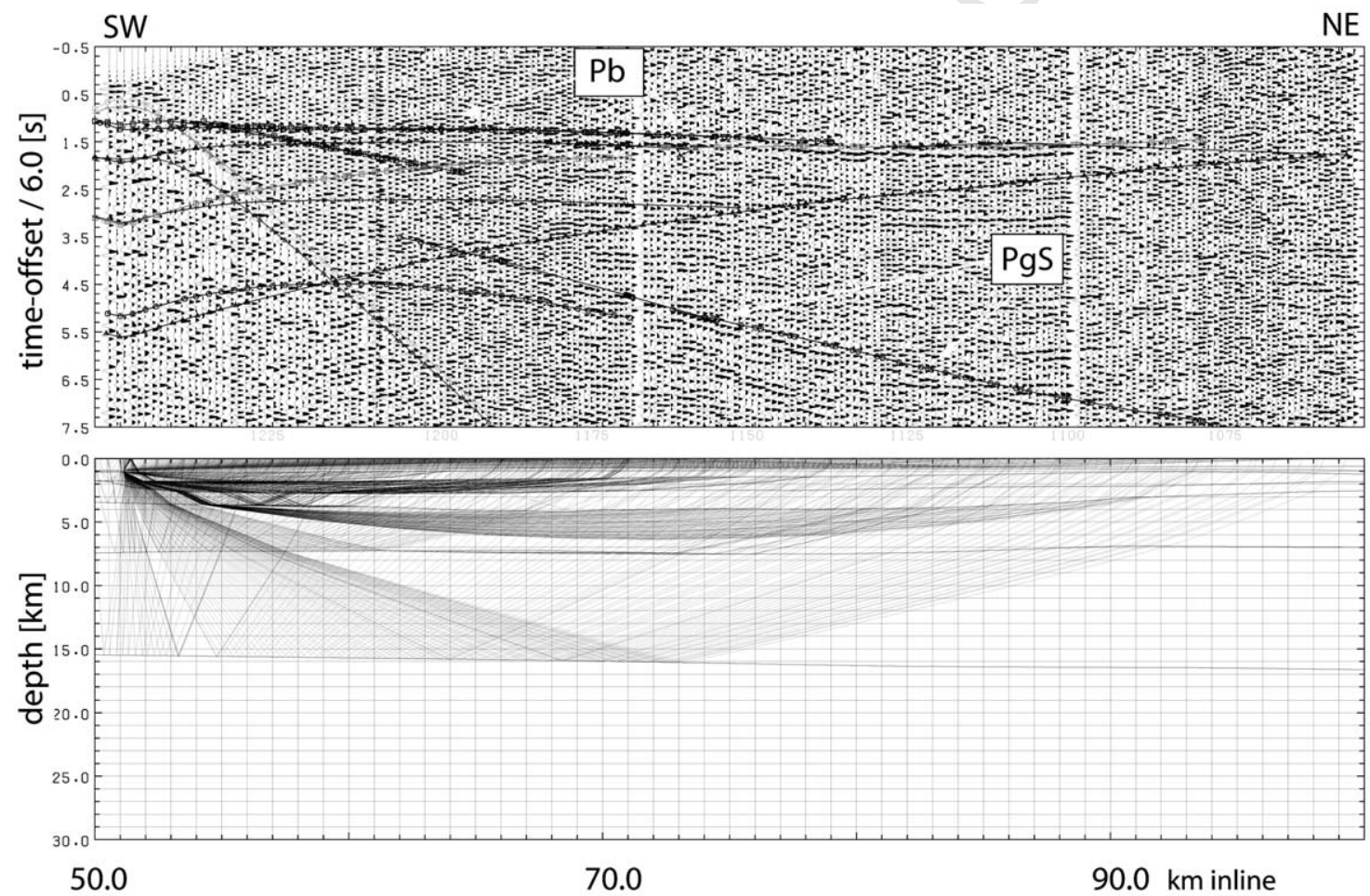

0.0

20.0

$40.0 \mathrm{~km}$ relative to OBS

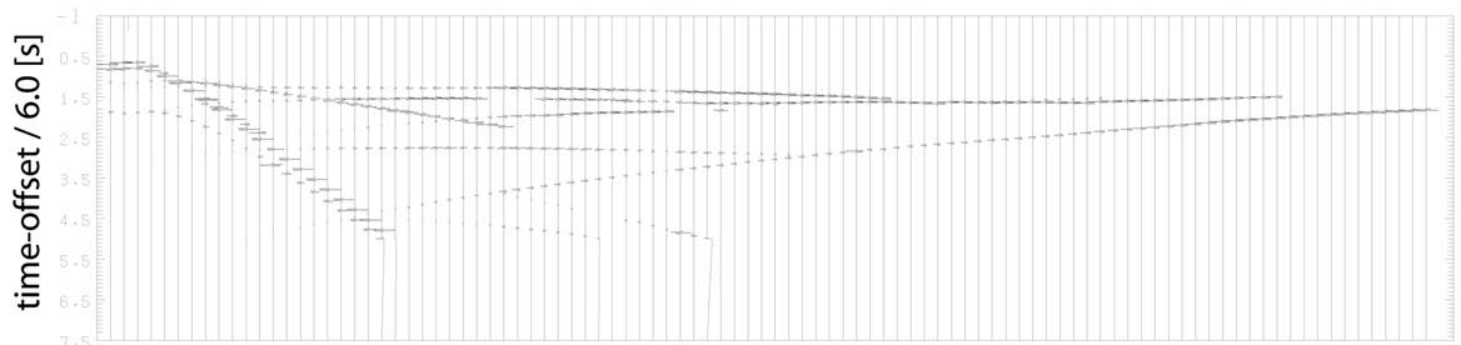

Fig. 7. Results obtained from OBS6 (located at the southwestern part of the seismic line, see Fig. 1b), which is characteristic for the data quality observed at this part of the seismic line. For explanation of phases and subfigures see Fig. 4. In addition, the lower part shows calculated amplitudes of synthetic traces. 
velocity increase to about $2.0 \mathrm{~km} / \mathrm{s}$. High-resolution MCS lines might identify however this layer probably has finer layering. A second sedimentary layer (S2) was identified along the central part of the line with a thickness of $250-1200 \mathrm{~m}$ and $\mathrm{v}_{\mathrm{p}} \approx 3.5 \mathrm{~km} / \mathrm{s}$. S2 strongly correlates with the lowermost sedimentary layer (S3, see Fig. 5) that reaches up to $2.3 \mathrm{~km}$ thickness while $\mathrm{v}_{\mathrm{p}}$ ranges between 3.9 and $4.4 \mathrm{~km} / \mathrm{s}$.

At the central part of the line a layer that extends laterally for more than $200 \mathrm{~km}$ separates S2 and S3. Its P-wave velocity was determined as $4.7-5.0 \mathrm{~km} / \mathrm{s}$. Implementing the results of the Deep Sea Drilling Project, site 336 (DSDP336, location is indicated in Fig. 1b) this layer is identified as basalt: DSDP336, that was drilled in 1974 at $811 \mathrm{~m}$ water depth penetrated down to $515 \mathrm{~m}$ below sea floor (bsf) and revealed the following results (Talwani et al., 1976): 1-159 $\mathrm{m}$ bsf = PlioPleistocene; 168-463 m bsf=late Oligocene-late Eocene (both layers with $\mathrm{v}_{\mathrm{p}}=1.6-1.76 \mathrm{~km} / \mathrm{s}$ ); 484-515 $\mathrm{m}$ bsf $=$ Basalt (dated to $43 \pm 3.3$ million years).

Three OBS sections are discussed here to elucidate the recordings from the basalt layer: OBS6 (Fig. 7) is an example for the sections from the SW with comparatively reduced data quality. The direct wave and subsequent phases from the uppermost sediments can hardly be identified, but at offsets of $15 \mathrm{~km}$ and more, the $\mathrm{P}_{\mathrm{b}}$ phase is well recorded (see Fig. 7). As no such $\mathrm{P}_{\mathrm{b}}$ recordings were obtained further towards the Iceland Basin we correlate the position of OBS6 with the
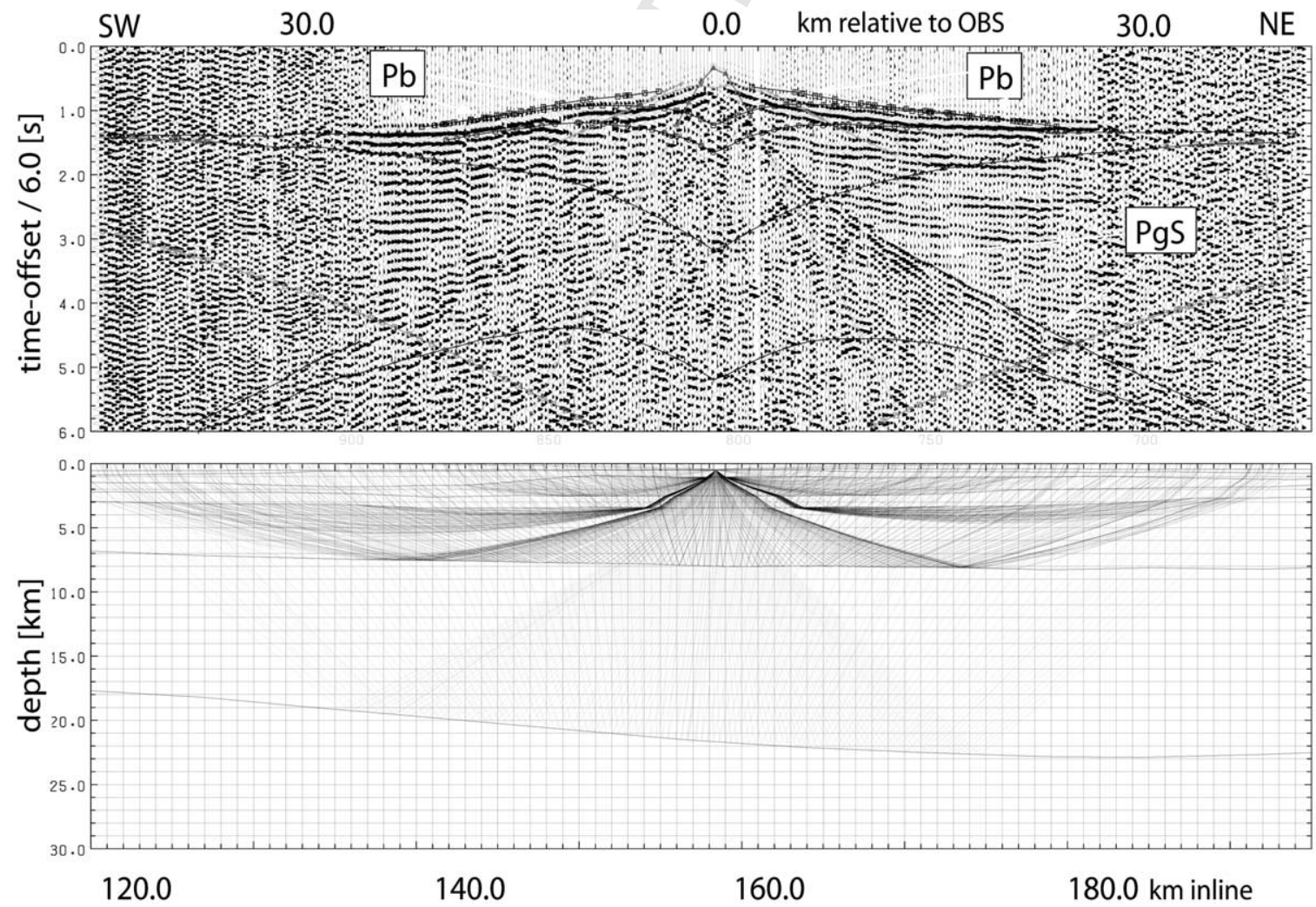

Fig. 8. Results obtained from OBS 19 (located at the central part of the seismic line, see Fig. 1b). This section is dominated by onsets from diving waves within the basalt $\left(\mathrm{P}_{\mathrm{b}}\right)$. For explanation of phases and subfigures see Fig. 4 . 
southwestern termination of the basalt layer. OBS19 (Fig. 8) is located further to the NE on top of the basalt. There, its maximum thickness of $1500 \mathrm{~m}$ was fixed by the maximum offsets of $\mathrm{P}_{\mathrm{b}}$ arrivals to either side of $23 \mathrm{~km}$ (SW) and $25 \mathrm{~km}(\mathrm{NE})$, respectively.

The north-eastern termination of the basalt is well documented by the recordings at OBS31 (see Fig. 9), which is one of the key-positions along the entire line. At $11 \mathrm{~km}$ offset to the NE a shift in
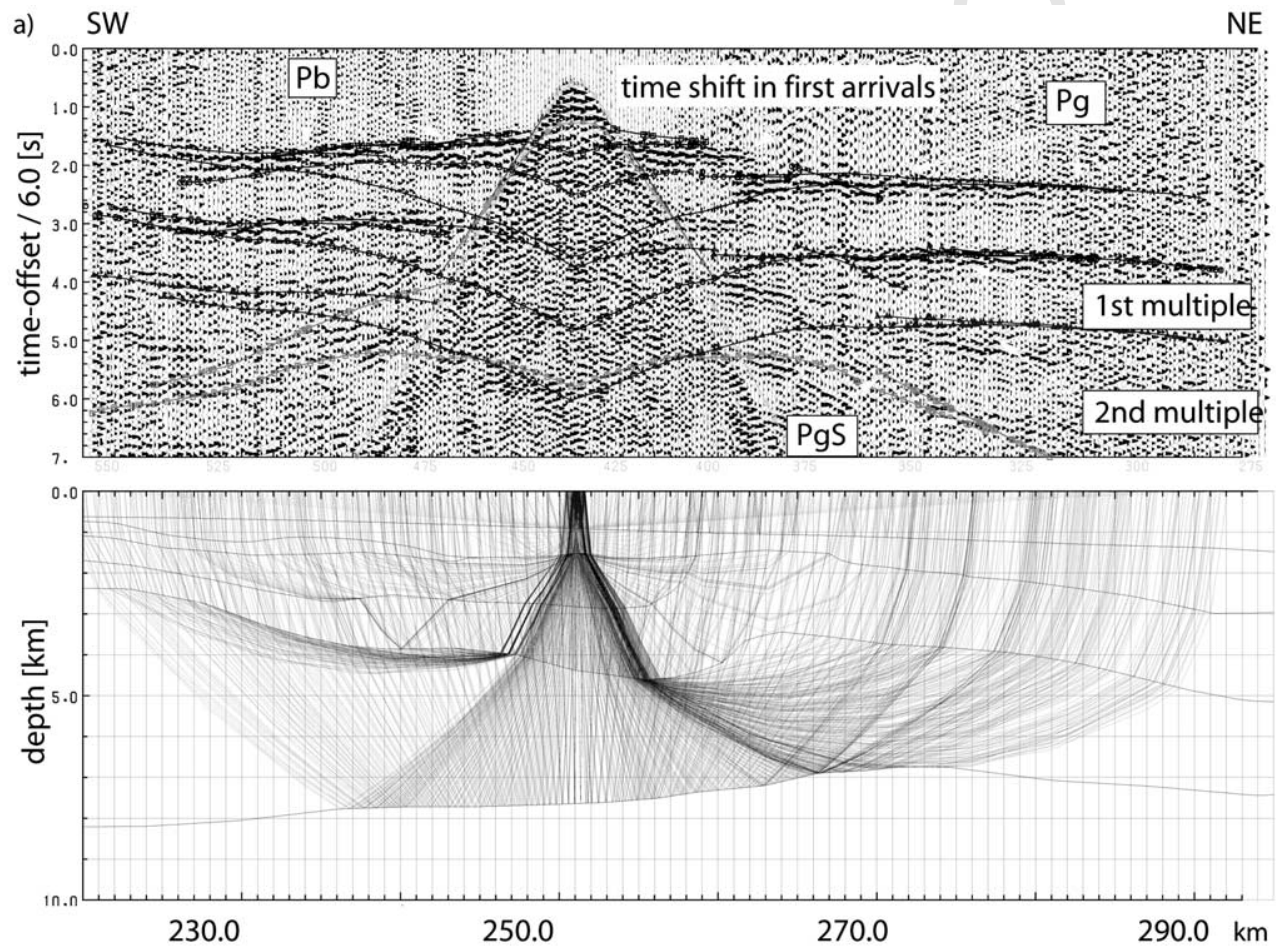

b)

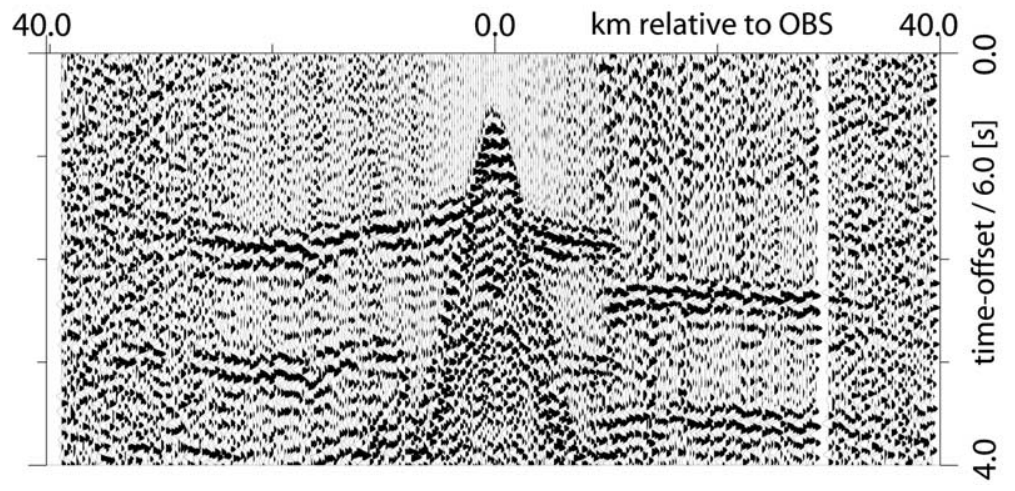

Fig. 9. (a) Results obtained from OBS 31 (located at the northeastern part of the seismic line, see Fig. 1b). A remarkable time-shift in first arrival times is identified to the NE indicating the northeastern boundary of the basalt layer and a velocity inversion below the basalt. For explanation of phases and subfigures see Fig. 4. (b) Near-field section of OBS 31 to elucidate the time shift as discussed in the text and the difference in maximum offsets of the $\mathrm{P}_{\mathrm{b}}$ phase to either side. 
first-arrival times of $0.6 \mathrm{~s}$ is observed (see Fig. 9b). This clearly indicates a low velocity layer (LVL) below the basalt. At larger offsets the $\mathrm{P}_{\mathrm{g}}$ becomes the first arrival. This time-shift allows to extrapolate the sedimentary layer S3 to below the basalt and thus to estimate thickness and velocity of the LVL as no direct information can be obtained from the LVL itself. Note that OBS31 is located in direct vicinity to DSDP336 and thus allows a direct calibration of our model for the uppermost approximately $500 \mathrm{~m}$. However, this is the first time that the structure within and especially below this basalt layer was penetrated.

\section{Discussion}

Analyzing the evolution and crustal origin of the Iceland-Faeroe region is of major importance when discussing the opening process of the North Atlantic between Greenland and the RockallFaeroe region in order to reconstruct the former coastal extent. Whereas the crust below Iceland was identified as abnormally thick oceanic crust formed by hot-spot activity (Palmason, 1971; Zverev at al., 1976; Gebrande et al., 1980; RRISP, 1980; Staples et al., 1997), the Faeroe block was found to be underlain by $30 \mathrm{~km}$ thick continental crust as part of the Caledonides (e.g. Bott et al., 1974). However, the exact location of the passive volcanic margin on the IFR was controversially discussed based on a number of studies that revealed partly contradicting results. In the following these are discussed and correlated with the model obtained in this study.

We identified a Moho depth between 15 and $23 \mathrm{~km}$. The maximum crustal thickness was observed below the crest of the ridge. The velocities obtained are typical for stretched continental crust (see e.g. Christensen and Mooney, 1995). We observed $v_{p} / v_{s}$ ratios of $1.73 \pm 0.04$ for the upper part of the crust which is not compatible with oceanic crust (see e.g. Mjelde et al., 2002). Thickness and velocity structure of the crust, its subdivision into an upper and a lower part by a first order discontinuity as well as the Poisson's ratio give clear indications for a continental origin of this part of the IFR. The deeper part of the velocity model is well constrained by wideangle phases obtained at numerous stations. $\mathrm{P}_{\mathrm{m}} \mathrm{P}$ amplitudes and $\mathrm{P}_{\mathrm{n}}$ arrivals point to an uppermost mantle velocity of $7.9 \mathrm{~km} / \mathrm{s}$ (see e.g. enlarged section of OBS 43 in Fig. 6b). Assuming that our line was close to the passive continental margin we would expect underplating by high-velocity $\left(\mathrm{v}_{\mathrm{p}}=7.2-7.7 \mathrm{~km} / \mathrm{s}\right)$ crustal bodies or intrusion by mafic melts related to the continental breakup in the early Tertiary as found by Eldholm and Grue (1994) for the passive volcanic margins of the North Atlantic. From our data we can exclude the presence of such an underplated body along the seismic line. Moreover, implementing such an underplated body in our model and calculating the subsequent arrival times we find no correlation with the recorded data: then the amplitudes of the $\mathrm{P}_{\mathrm{m}} \mathrm{P}$ arrivals are too weak and the slope of the $\mathrm{P}_{\mathrm{n}}$ phase is not appropriate. Taking into consideration the range of $v_{p}$ in the uppermost mantle allowed by our data we relate the sub-crustal structure to represent anomalously hot uppermost mantle rather than an underplated body typical for rifted volcanic margins as observed e.g. in the outer Rockall region where Vogt et al. (1998) identified an underplated body of $10 \mathrm{~km}$ thickness with a lateral extension of about $80 \mathrm{~km}$. Interestingly, the crustal structure observed near this underplated body towards the continental crust of the Caledonides is very similar in thickness and velocity structure to that of our model. This supports our conclusion that the south-eastern part of the IFR is of continental origin and thus belongs to Paleo-Europe. 
We identified an up to $1.5 \mathrm{~km}$ thick basalt layer $\left(\mathrm{v}_{\mathrm{p}}=4.7-5.0 \mathrm{~km} / \mathrm{s}\right)$ that was drilled by DSDP336 and dated to $43 \pm 3.3$ million years (Talwani et al., 1976). The lateral extension across the IFR (SW-NE) was found to be about $200 \mathrm{~km}$ and corresponds well with the lateral extension of the NAVP (e.g. Dickin, 1988; summarized in Eldholm and Grue, 1994). However, different to high-resolution MCS techniques the wide aperture seismic method applied here allows penetrating structures within and below energy absorbing layers such as basalt as seismic energy at sufficient offsets is observed. This allows us to define the structure (direct) and velocity (indirect) of the LVL below the basalt that was drilled at its uppermost part by DSDP336. Based on the limited offsets of the $\mathrm{P}_{\mathrm{b}}$ phase we were able to define the thickness of the basalt. Moreover, the leaking continuing arrivals of a $\mathrm{P}_{\mathrm{g}}$ phase in addition with the time shift in first arrivals at OBS 31 (Fig. 9) that is located close to the north-eastern termination of the basalt give clear indication for a velocity inversion below the basalt. Thus we can exclude that the basalt layer formed on abnormally thick oceanic crust or even belonging to oceanic crust formed by sea-floor spreading during opening of the North Atlantic. Instead, it was deposited on top of Mesozoic sediments. This indicates that this region has to be much older than the basalt itself, stressing that the crust below could hardly have been formed by magma flow during opening of the North Atlantic.

Relating our model to the results of Bott et al. (1971), and especially their line 69/2 that crosses our profile perpendicularly in the central part, we note that they obtained $\mathrm{a}_{\mathrm{p}}=7.84 \mathrm{~km} / \mathrm{s}$ reflector at a depth of only about $16 \mathrm{~km}$ based on arrival times from three shots. Incorporating their velocity of $\mathrm{v}_{\mathrm{p}}=5.8 \mathrm{~km} / \mathrm{s}$ for almost the entire depth range above that reflector, we find that the mean crustal velocity as determined in our study $(>6.0 \mathrm{~km} / \mathrm{s})$ forces this reflector to be somewhat deeper at depth levels where we identified the Moho. Bott and Gunnarsson (1985) reevaluated the crustal structure of the IFR using the same seismic data as Bott et al. (1971). Still, the segment of their profile, which is also covered by our data, has a comparatively poor coverage. However, they obtained a $7.8 \mathrm{~km} / \mathrm{s}$ refractor at depths between 28 and $30-35 \mathrm{~km}$ below the ridge, which they interpreted as the Moho. Again this refractor might be related to the Moho as obtained by our line at $23 \mathrm{~km}$ depth below the crest of the ridge assuming crustal velocities as obtained in this study. Although the thickness obtained by Bott and Gunnarsson (1985) is more typical for continental crust the authors interpret the crust beneath the ridge to be formed by seafloor spreading between 55 and 40 million years ago.

In the 1990, a large-scale seismic refraction experiment, the so-called FIRE line, was carried out extending from Iceland to the Faeroe Islands along the entire IFR and resulted in a velocity model down to $55 \mathrm{~km}$ depth (Richardson et al., 1998; Smallwood et al., 1999). Based on their seismic data, Richardson et al (1998) discuss two alternative models of which the first one would meet the velocity-depth distribution found along our line quite well. However, the model they favor cannot explain any of our traveltime sections, especially the strong $\mathrm{P}_{\mathrm{m}} \mathrm{P}$ reflections generated by a velocity contrast of about $0.9 \mathrm{~km} / \mathrm{s}$ at the Moho at $23 \mathrm{~km}$ depth below the crest of the ridge were both lines intersect. Furthermore, Richardson et al. (1998) state to have mapped the transition from continental Faeroe to thickened oceanic crust of the Faeroe-Iceland Ridge 100 to $40 \mathrm{~km} \mathrm{NW}$ of the Faeroe Islands based on lateral variation of $v_{p}$ in the upper crust. The IFR itself was interpreted to be composed of $>30 \mathrm{~km}$ thick oceanic crust based on seismic and gravity modeling. Due to the receiver-source geometry of the FIRE line the upper crustal structure remained unresolved: The basalt layer drilled by DSDP336 and also identified in our model was not resolved and as a consequence no conclusion on the origin of the ridge could be drawn based 
on the sedimentary sequences. In a later study that combined the same seismic data set as well as MCS high-resolution data for the uppermost $1 \mathrm{~km}$, Smallwood et al. (1999) obtained a Moho depth of $27-28 \mathrm{~km}$ for the southeastern IFR. Again, the ridge in this part was interpreted to be of oceanic origin.

When analysing the crustal origin of regions close to a spreading center such as the MidAtlantic Ridge, the distribution of magnetic anomalies may serve to provide additional information. A map of residual total magnetic intensity along the IFR constructed by Fleischer (1971) shows large amplitudes and short wavelength magnetic anomalies that cannot be associated with a lineation pattern. Implementing gravity modeling, Bott et al. (1971) conclude that despite the absence of characteristic magnetic lineations on the ridge the IFR must have been formed by seafloor spreading leading them to propose the crustal boundary to be located at the bathymetric scarp of the NW Faeroe shelf edge. In contrast, paleomagnetic reconstruction would favor a more northwesterly location (Bott, 1985). For a thorough overview on the magnetic anomalies in the Iceland-Faeroe region we combined data from a large number of marine surveys (see Fig. 10a). The region to either side of the Mid-Atlantic Ridge as well as the Iceland and Norway basins exhibit a clear lineation pattern typical for crust formed by sea-floor spreading. In contrast, the distribution on the IFR is far more complex. Therefore we enlarged the part of the map being of major interest here (Fig. 10b). This allows distinguishing two different patterns along the IFR. Whereas the north-western part towards Iceland shows a lineation pattern similar to a typical anti-parallel distribution, the distribution of anomalies further in the southeast (including our seismic line) towards the Faroe block is different. There, no lineation of anomalies is identified, but, in contrast, the distribution of anomalies is highly similar to that identified further to the southeast on continental Europe. A crustal transition may be identified approximately 100 $\mathrm{km}$ to the NW of our line. This supports our interpretation of continental crust below the southeastern IFR.

On the slope from the IFR towards the Norway Basin (see Fig. 2) we observed a lateral increase of $v_{p}$ throughout the entire crust. Further to the NE, where the water depth exceeds $2000 \mathrm{~m}$, thickness and velocity structure allow the identification of a rather sharp crustal transition towards the oceanic crust below the Norway Basin. We call this a rather sharp continent-ocean boundary due to the consequently decreasing crustal thickness towards the NE that comes along with increasing P-wave velocities. The transition in velocity is believed to be rather sharp; however the receiver-source geometry was not designed to map lateral changes within a few kilometres. Thus, our model reflects this boundary not s sharp as it really is but somewhat smeared in lateral direction.

Comparing this part of the profile to the southwestern end of the line (towards the Iceland Basin) we cannot make judgment on a similar lateral variation within the crust due to comparatively poor coverage (as discussed above). However we state that no sharp velocity discontinuity within the sediments was observed similar to that towards the Norway Basin $\left(\mathrm{v}_{\mathrm{p}}=2.0\right.$ to $4.0 \mathrm{~km} /$ $\mathrm{s})$. This might indicate that our line does not cover the crustal transition towards the oceanic crust of the Iceland Basin. This is supported by the waterdepth that does not exceed $1100 \mathrm{~m}$ at the SW end of our line.

The sedimentary sequences allow the reconstruction of the evolution of this part of the IFR back to Cretaceous time. The lowermost sediment (S3, see Fig. 2) with $\mathrm{v}_{\mathrm{p}}$ of up to $4.5 \mathrm{~km} / \mathrm{s}$ is interpreted as pre-Eocene and therefore syn-rift sediment. Since no sediments of Miocene age are 

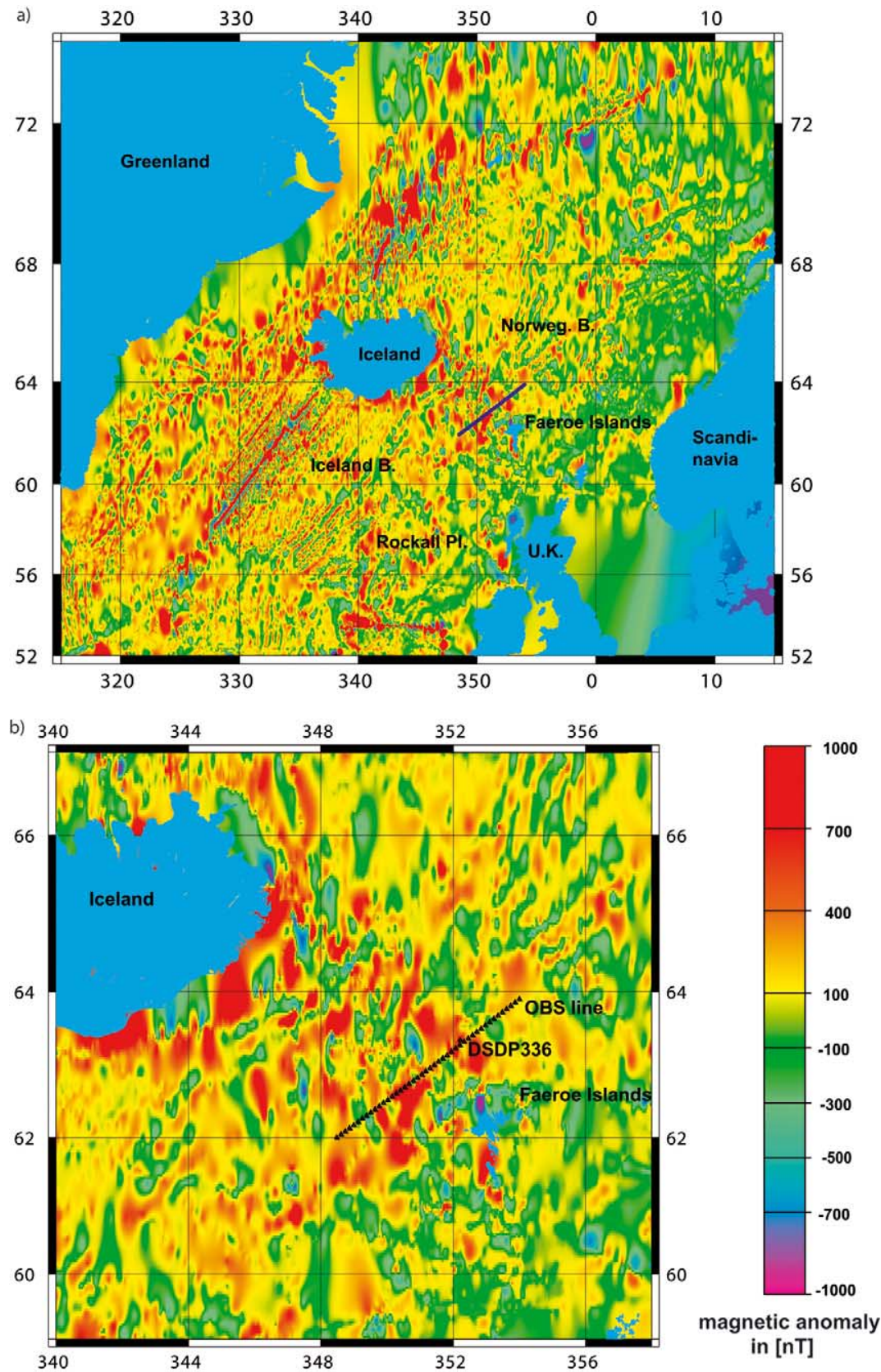

Fig. 10. (a) Distribution of magnetic anomalies in the North Atlantic computed from various marine surveys. The distribution of anomalies allows identifying a clear lineation pattern along the Mid-Atlantic Ridge and subsequent regions. In contrast, regions with a diffuse distribution of anomalies are identified. (b) Distribution of magnetic anomalies in the Iceland-Faeroe region (same data set as in a) A clear difference between the northwestern part of the IFR (with magnetic lineation pattern similar to that along the Reykjanes Ridge) and the southeastern part of the IFR where a diffuse distribution of anomalies (similar to the continental Rockall region) is observed. 
observed here, we conclude that this part of the IFR underwent an uplift resulting in erosion at that time. The uppermost sedimentary layer (S1) with velocities between 1.7 and $2.0 \mathrm{~km} / \mathrm{s}$ was dated as Pliocene from the DSDP336 borehole (Talwani et al., 1976) indicating a reactivation of subsidence in the last two million years resulting in a high sedimentation rate. Comparing results of DSDP boreholes from other aseismic ridges, Detrick et al. (1977) concluded that parts of the IFR have been at sea level for an abnormally long period of $15 \mathrm{Ma}$. This is well supported by our data and might be explained by a rather thick crust already at that time (no isostatic equilibrium). A similar sedimentary structure as resolved by our data was identified by Vogt et al. (1998) who analyzed seismic data obtained in the Rockall region across the Hatton Continental Margin. There, a strong velocity contrast within the sediments suggests an erosional unconformity surface between syn-rift and post-rift layers that was interpreted to have developed due to regional uplift driven by up welling of hot asthenosphere before anomaly 24 (early Eocene) time. Correlation with our model suggests that this process might have occurred on the IFR as well.

Implementing the results from DSDP336 with regards to earlier ocean water circulation we come to the conclusion that the IFR has undergone subsidence. An emergent ridge would act as the Thulean land bridge for mammals between Eurasia and America, and also prevent the Arctic and Atlantic waters and the marine fauna from mixing across this boundary. As the basalt (penetrated by DSDP336 and identified in our seismic line) was deposited subaerially (Talwani et al., 1976), the IFR must have subsided by at least $1300 \mathrm{~m}$ since the middle Miocene stressing its role for evaluating former global water circulation. The fauna evidence at DSDP sites 336 and 352 (see Fig. 1b for location) suggests that there was indeed a barrier to circulation between these two sites until late Oligocene times. The idea of a Tertiary land bridge forming the present IFR is, however, not in conflict with the opening process of the eastern part of the North Atlantic. When the Norway Basin and Lofoten Basin first began to form as a result of sea-floor spreading in the Norwegian Sea, these basins were cut off by the IFR from the Atlantic to the south (Talwani and Udintsev, 1977) with the resulting consequences for ocean water circulation.

\section{Conclusions}

We have presented the results of a wide aperture seismic survey conducted on the southeastern part of the IFR perpendicular to its strike. We identified a Moho depth between 15 and $23 \mathrm{~km}$. The maximum crustal thickness was observed below the crest of the ridge. Thickness and velocity structure of the crust, its subdivision into an upper and a lower part by a first order discontinuity as well as the Poisson's ratio give clear indications for a continental origin for this part of the IFR. An up to $1.5 \mathrm{~km}$ thick basalt layer that was also identified by DSDP336 and dated to $43 \pm 3.3$ million years was found to extend laterally about $200 \mathrm{~km}$ along the crest of the IFR. However, the velocity inversion identified below the basalt stress that this region is somewhat older than the basalt itself $(43 \pm 3.3 \mathrm{Ma})$ indicating that the crust below could hardly have been formed by magma flow during opening of the North Atlantic.

Analyzing the distribution of magnetic anomalies in the area of investigation we find good correlation with our model. The distribution of magnetic anomalies along the IFR allows identifying the passive continental margin from continental Rockall-Faeroe-Voering region as part of Paleo-Europe towards the oceanic domain formed by the Iceland hot spot to be located 
approximately $100 \mathrm{~km}$ to the NW of our seismic line. Thus, the discussion of a Tertiary land bridge today represented by the southeastern part of the IFR needs to be re-evaluated with all its implications on global water circulation. Moreover, our results may be of fundamental economic interest concerning the hydrocarbon potential of this region that has not yet been evaluated and remains virtually unknown.

\section{Uncited references}

Palmason, 1965 is not cited in the text.

\section{Acknowledgements}

We would like to thank the officers and crew of the R/V Prof. Sthokman for their great support during the entire survey. Furthermore each of the participants is thanked for the valuable assistance, especially Mr. Leonid Akentiev for his skillful operation of the 60-liter sleeve guns and the party-chief Knuth Lange. For the entirely good co-operation we thank Prof. Savostin and V. Sedov from the Shirshov Institute of Oceanology, Russian Academy of Sciences in Moscow. Spelling corrections by S. Thomson are gratefully acknowledged. We thank two anonymous reviewers for their constructive criticism.

\section{References}

Bohnhoff, M., Makris, J., Papanikolaou, D., Stavrakakis, G., 2001. Crustal investigation of the Hellenic subduction zone using wide aperture seismic data. Tectonophysics 343, 239-262.

Bott, M.H.P., 1985. Plate tectonic evolution of the Icelandic Traverse Ridge and adjacent regions. J. Geophys. Res. 90 (B12), 9953-9960.

Bott, M.H.P., Gunnarsson, K., 1985. Crustal Structure of the Iceland-Faeroe Ridge. J. Geophys 47, $221-227$.

Bott, M.H.P., Browitt, C.W.A., Stacey, A.P., 1971. The deep structure of the Iceland-Faeroe Ridge. Mar. Geophys. Res. 1, 328-351.

Bott, M.H.P., Sunderland, J., Smith, P.J., Casten, U., Saxov, S., 1974. Evidence for continental crust below the Faeroe Islands. Nature 248, 202-204.

Červeny, V., Psenćik, I., 1981. Two-dimensional two point raytracing package. Charles University, Prague, Czech Republic.

Červeny, V., Psenćik, I., 1983. Guide to the program package SEIS83. Charles University, Prague, Czech Republic.

Christensen, N.I., Mooney, W.D., 1995. Seismic velocity structure and composition of the continental crust: A global view. J. Geophys. Res. 100 (B7), 9761-9788.

Detrick, R.S., Sclater, J.G., Thiede, J., 1977. The subsidence of aseismic ridges. Earth and Planet. Sci. Lett. 34, 185196.

Dickin, A.P., 1988. The North Atlantic Tertiary Province. In: Macdougall, J.D. (Ed.), Continental Flood Basalts. Kluwer Academic, Hingham, Mass, pp. 111-149.

Eldholm, O., Grue, K., 1994. North Atlantic volcanic margins: Dimensions and production rates. J. Geophys. Res. 99 (B2), 2955-2968.

Fleischer, U., 1971. Gravity surveys over the Reykjanes Ridge and between Iceland and the Faeroe Islands. Mar. Geophys. Res. 1, 314-327. 
Foulger, G.R., Du, Z., Julian, B.R., 2003. Icelandic-type crust. Geophys. J. Int 155, 567-590.

Gebrande, H., Miller, H., Einarsson, P., 1980. Seismic Structure of Iceland along RRISP-Profile I. J. Geophys 47, 239 249.

Makris, J., Ginzburg, A., 1987. The Afar depression: transition between continental rifting and sea-floor spreading. Tectonophysics 141, 199-214.

Makris, J., Möller, L., 1989. An Ocean Bottom Seismic Station for General Use, Technical Requirements and Applications. In: Europe and the Sea, Hoefeld, J. Mitzlaff, A., Polomsky, S. (Editors), 196-211.

Makris, J., Egloff, F., Rihm, R., 1999. WARRP (Wide Aperture Reflection and Refraction Profiling): The principle of successful data acquisition where conventional seismic fails. Extended Abstract, 69th meeting of the Society of Exploration Geophysics (SEG), Houston, 989-992.

Makris, J., Lange, K., Savostin, L., Sedov, V., 1995. A wide-angle reflection profile across the Iceland-Faeroe Ridge, in: Croker, P.F. and Shannon, P.M. (eds.): The petroleum Geology of Ireland's Offshore Basins, Geological Society Special Publication No. 93, 459-466.

McKenna, M.C., 1972. Eocene final separation of the Eurasian and Greenland-North American Landmasses. Reports on the International Geological Congress 24 (7), 275-281.

Mjelde, R., Aurvag, R., Kodaira, S., Shimamura, H., Gunnarsson, K, Nakanishi, A., Shiobara, H., 2002. Vp/Vs-ratios from the Kolbeinsey Ridge to the Jan Mayen Basin, North Atlantic; implications for lithology, porosity and presentday stress field. Mar. Geophys. Res. 23, 125-145.

Myhre, A.M. and Thiede, J. (1995). North Atlantic - arctic gateways. In: Myhre, A.M., Thiede, J. and Firth, J.V., et al., Proceedings of the Ocean Drilling Program, Initial Reports, Vol. 151, 5-26.

Palmason, G., 1965. Seismic refraction measurements of the basalt lavas of the Faeroe Islands. Tectonophysics 2, 475482.

Richardson, K.R., Smallwood, J.R., White, R.S., Snyder, D.B., Maguire, P.K.H., 1998. Crustal structure beneath the Faeroe Islands and the Faeroe-Iceland Ridge. Tectonophysics 300, 159-180.

RRISP Working Group, 1980. Reykjanes Ridge Iceland seismic experiment (RRISP77). J. Geophys. 47, 228-238.

Samson, C., Barton, P.J., Karwatowski, J., 1995. Imaging beneath an opaque basaltic layer using densely sampled wide-angle OBS. Geophysical Prospecting 43, 509-527.

Smallwood, J.R., Staples, R.K., Richardson, R., White, R.S., 1999. Crust generated above the Iceland mantle plume: From continental rift to oceanic spreading center. J. Geophys. Res. 104 (B10), 22885-22902.

Staples, R.K., White, R.S., Brandsdottir, B., Menke, W., Maguire, P.K.H., McBride, J.H., 1997. Faeroe-Iceland Experiment 1. Crustal structure of northeastern Iceland. J. Geophys. Res. 102 (B4), 7849-7866.

Strauch, V.F., 1970. The Thule land bridge as routeway and faunal barrier between the Atlantic and the Norwegian Sea in the Tertiary (in German). Geologische Rundschau 60-1, 381-417.

Talwani, M. et al., 1976. Site reports: Sites 336 and 352, in: Initial Reports on the Deep Sea Drilling Project 38, $23-116$. Talwani, M., Udintsev, G., 1977. Initial reports of the Deep Sea Drilling Project, chapter 34: Tectonic synthesis, Volume 38, Dublin-Amsterdam, 1213-1242.

Tarling, D.H., Gale, N.H., 1968. Isotopic dating and paleomagnetic polarity in the Faeroe Islands. Nature London 218 (5146), 1043-1044.

Trey, H., Cooper, A., Pellis, G., della Vedova, B., Cochrane, G., Brancolini, G., Makris, J., 1999. Transect across the West Antarctic rift system in the Ross Sea, Antarctica. Tectonophysics 301, 61-74.

Vogt, U., Makris, J., O’Reilly, B.M., Hauser, F., Readman, P.W., Jakob, A.W.B., Shannon, P., 1998. The Hatton Basin and continental margin: Crustal structure from wide-angle seismic and gravity data. J. Geophys. Res. 103 (B6), $12545-12566$.

White, R.S., 1989. Initiation of the Iceland plume and opening of the North Atlantic, in: Extensional Tectonics and Stratigraphy of the North Atlantic Margins, edited by A.J. Tankard and H.R. Balkwill, AAPG Mem. 46, 149-154.

Zelt, C.A., Smith, R.B., 1992. Seismic travel time inversion for 2D crustal velocity structure. Geophys. J. Int 108, 1634.

Zelt, C.A., 1997. RAYINVR: Documentation and related programs, version 1.4.2.; manual, Rice University, Texas, USA.

Zverev, S.M., Kosminskaya, I.P., Krasilstchikova Mikhota, G.G., 1976. The crustal structure of Iceland and the Iceland-Faeroe-Shetland region. Soc. Sci. Isl 5, 73-93. 